\title{
Retraction: NEAT1 Overexpression Indicates a Poor Prognosis and Induces Chemotherapy Resistance via the miR-491-5p/SOX3 Signaling Pathway in Ovarian Cancer
}

\author{
Frontiers Editorial Office*
}

\section{A Retraction of the Original Research Article}

OPEN ACCESS

Approved by:

William C. Cho,

$Q E H$, Hong Kong SAR, China

*Correspondence: Frontiers Editorial Office editorial.office@frontiersin.org

Specialty section: This article was submitted to RNA a section of the journal

Frontiers in Genetics

Received: 24 January 2022 Accepted: 24 January 2022 Published: 31 January 2022

Citation: Frontiers Editorial Office (2022) Retraction: NEAT1 Overexpression Indicates a Poor Prognosis and Induces Chemotherapy Resistance via

the miR-491-5p/SOX3 Signaling

Pathway in Ovarian Cancer.

Front. Genet. 13:861109.

doi: 10.3389/fgene.2022.861109
NEAT1 Overexpression Indicates a Poor Prognosis and Induces Chemotherapy Resistance via the miR-491-5p/SOX3 Signaling Pathway in Ovarian Cancer by Jia, X., Wei, L., and Zhang, Z. (2021). Front. Genet. 12:616220. doi:10.3389/fgene.2021.616220

The journal and Chief Editors retract the 29 April 2021 article cited above.

Following publication, concerns were raised regarding the validity of the data in the article. The authors failed to provide the raw data or a satisfactory explanation during the investigation, which was conducted in accordance with Frontiers' policies. Given the concerns, and the lack of raw data, the editors no longer have confidence in the findings presented in the article.

This retraction was approved by the Chief Editors of Frontiers in Genetics and the Chief Executive Editor of Frontiers. The authors have not responded to any correspondence regarding the retraction.

\section{PUBLISHER'S NOTE}

All claims expressed in this article are solely those of the authors and do not necessarily represent those of their affiliated organizations, or those of the publisher, the editors and the reviewers. Any product that may be evaluated in this article, or claim that may be made by its manufacturer, is not guaranteed or endorsed by the publisher.

Copyright (c) 2022 Frontiers Production Office. This is an open-access article distributed under the terms of the Creative Commons Attribution License (CC BY). The use, distribution or reproduction in other forums is permitted, provided the original author(s) and the copyright owner(s) are credited and that the original publication in this journal is cited, in accordance with accepted academic practice. No use, distribution or reproduction is permitted which does not comply with these terms. 